\title{
SOSIALISASI PRAKTIK DAN PERLINDUNGAN PENGGUNA INTERNET DI SMA NEGERI 1 SUNGAI LIAT
}

\author{
Suryati $^{1}$, Ramanata Disurya ${ }^{2}$, Ermini ${ }^{3}$, Layang Sardana ${ }^{4}$, Sri Husnulwati ${ }^{5}$, Sri \\ Wahyuningsih ${ }^{6}$, Jumroh $^{7}$
}

1,2,3,4,5,6,7 FKIP Universitas PGRI Palembang

\begin{abstract}
Abstrak
Tujuan dari pelaksanaan Pengabdian Kepada Masyarakat (PKM) di SMA Negeri 1 Sungai Liat adalah (1) siswa dapat memahami dan mengidentifikasi bahaya penggunaan internet/media sosial, (2) siswa dapat memahami dan mengidentifikasi bentuk perlindungan pengguna internet/media sosial. Kegiatan PKM ini dilaksanakan selama 1 (satu) hari dengan jumlah peserta 60 orang siswa. Metode yang digunakan dalam melaksanakan kegiatan PKM ini adalah dengan metode ceramah, diskusi dan tanya jawab. Hasil yang diperoleh selama kegiatan PKM yaitu adanya peningkatan pemahaman siswa terkait bahaya penggunaan internet serta perlindungan pengguna internet sebesar $73 \%$ jika ditinjau dari perbandingan hasil pre test dan post test. Jika melihat rata-rata (mean) secara keseluruhan sebenarnya cukup mengembirakan, hal ini dikarenakan siswa yang menyatakan kegiatan berjalan sangat baik dan baik adalah sekitar $37 \%$ (22 orang), cukup baik sekitar 24, $1 \%$ (14 orang).
\end{abstract}

Kata Kunci : praktik, perlindungan, internet, siswa

\begin{abstract}
The implementation of community service at SMA Negeri 1 Sungai Liat objective is to encourage students to understand and identify the risks of internet/social media uses, and also to help students in order to understand and identify the forms of protection for internet/social media users. The length of this activity is one day with 60 students as participants. The methods used for this community service activity are lecture, discussion, and question-answer. The result obtained during the community service activity is the increasing number of students who understand the risks of internet use. The result shows that there was $73 \%$ of increasing number for students who understand the risk of internet use as well as the protection of internet usage based on the results comparison of pretest and post-test. The result form the overall mean is satisfying as there is $37 \%$ or 22 students who agreed that the activity was running very smoothly and $24,1 \%$ or 14 students agreed that the activity was run smoothly.
\end{abstract}

Keywords : Practice, Protection, Internet, Student

Correspondence author: Suryati, suryatilasnai@gmail.com, Indonesia

This work is licensed under a CC-BY-NC

\section{PENDAHULUAN}

Internet adalah sistem jaringan komputer global yang saling terhubung menggunakan protokol internet (TCP/IP) untuk menghubungkn perangkat di komputer di seluruh dunia. Internet adalah jaringan dari banyak jaringan yang terdiri dari jaringan 
pribadi, umum, akademik, bisnis, dan pemerintah lokal. Dihubungkan oleh barisan bahasa pemrograman yang luas dan mencakup peralatan elektronik, nirkabel, dan teknologi jaringan optik. Internet memberikan berbagai sumber informasi dan jasa, seperti akses World Wide Web (WWW), surat elektronik, telepon, dan jaringan peer-topeer untuk saling berbagi berkas (Hoffman dan Harris, 2006). Penggunaan internet yang tidak terkontrol akan menyebabkan banyak kerugian. Penggunaan internet oleh anak yang tidak terkontrol oleh orang tua akan memberi efek buruk pada kehidupan sosial dan psikologis anak-anak, bahkan akademik mereka (Jackson, dkk, 2003).

Perilaku Anak dan Remaja dalam Menggunakan Internet setidaknya 30 juta anakanak dan remaja di Indonesia merupakan pengguna Internet, dan media digital saat ini menjadi pilihan utama saluran komunikasi yang mereka gunakan. Studi ini menemukan bahwa 98 persen dari anak-anak dan remaja yang disurvei tahu tentang Internet dan bahwa 79,5 persen diantaranya adalah pengguna Internet (Kemenkominfo, 2014).

Saat ini bidang komunikasi dan informatika di Indonesia terus berkembang terutama internet. Menurut data Asosiasi Penyelenggara Jasa Internet Indonesia (APJII) menyatakan bahwa pertumbuhan pengguna internet di Indonesia meningkat 34,9\% pada tahun 2015 (Maulana,2015) dan menurut Kemkominfo jumlah pengguna internet di Indonesia mencapai 82 juta orang dan berada pada peringkat ke-8 dunia. Dari jumlah tersebut, 80 persen diantaranya adalah remaja berusia 15-19 tahun. Layanan yang paling banyak digunakan oleh pengguna internet di Indonesia pada urutan tiga teratas yaitu, instant messaging, E-mail dan social networking. Dari perkembangan internet di Indonesia tidak hanyak memunculkan dampak positif, yaitu memudahkan kehidupan manusia dalam berkomunikasi dan mencari informasi namun terdapat sisi negatif yang memiliki efek buruk bagi individu maupun kelompok yang tidak hanya merugikan secara material tetapi juga mental dan menyebabkan kematian. Sisi negatif dari penggunaan internet antara lain cyberbullying, cybercrime, cyberstalking, gambling, pornografi, penipuan online dan lain sebagainya.

Pengguna internet telah meningkat setiap waktu. Internet adalah sebuah sistem informasi global yang terhubung secara logika oleh address yang unik secara global yang berbasis pada Internet Protocol (IP), mendukung komunikasi dengan menggunakan TCP/IP, menyediakan, menggunakan, dan membuatnya bisa diakses baik secara umum maupun khusus (Greenlaw \& Hep, 2001). Sumber lain mendefinisikan internet sebagai sebuah jaringan besar yang menghubungkan jaringan komputer baik dari organisasi bisnis, organisasi pemerintahan, dan sekolah-sekolah dari seluruh dunia secara langusung dan cepat (Turban, Rainer, \& Potter, 2005). Penggunanya dapat mencakup semua usia, dari kalangan kanak-kanak sampai dewasa. Begitu pula dengan dunia pendidikan, internet telah menjadi salah satu fasilitator utama dalam pelaksanaan proses belajar mengajar pada institusi-institusi pendidikan di seluruh penjuru dunia. Digitalisasi bahkan telah diimplementasikan pada institusi pendidikan di negara-negara berkembang di seluruh dunia, seperti pengajaran menggunakan presentasi digital, pengumpulan tugas secara online dan lain sebagainya. Siswa maupun pengajar secara tidak langsung dituntut untuk menguasai berbagai alat maupun perangkat lunak teknologi informasi mengingat perangkat keras dan perangkat lunak tersebut sebagai fondasi dari berjalannya sebuah teknologi informasi.

Sebagaimana uraian yang telah diberikan pada halaman sebelumnya, bahwa saat ini terlalu banyak muncul berita bohong (hoax), ujaran kebencian (hate speech), bercandaan seperti body shaming serta tindakan kriminal oleh remaja sebagai generasi milenial yang diakibatkan oleh akibat buruk penggunaan teknologi dalam hal ini 
internet. Arus informasi yang semakin pesat saat ini tidak disertai oleh pengetahuan yang cukup tentu sangat rentan memberi dampak buruk terhadap perkembangan remaja sebagai pengguna aktif internet.

Untuk mengantisipasi hal ini terus terjadi dan semakin berkembang, maka dilakukan sosialisasi mengenai bagaimana praktik penggunaan internet serta aturan yang harus dipahami oleh siswa dalam menggunakan intenet. Sosialisasi mengenai praktik dan perlindungan terhadap pengguna internet untuk generasi milenial dilakukan di SMA Negeri 1 Sungai Liat, Kabupaten Bangka, Kepulauan Bangka Belitung.

\section{METODE PELAKSANAAN}

Rancangan mekanisme pelaksanaan kegiatan PkM ini dilakukan dengan mengadopsi langkah-langkah action research yang terdiri dari 4 (empat) tahapan, yaitu: perencanaan, tindakan, observasi dan evaluasi, serta refleksi. Kegiatan-kegiatan atau aktivitas-aktivitas dari masing-masing tahapan adalah sebagai berikut.

1. Perencanaan

Kegiatan-kegiatan yang dilakukan pada tahap perencanaan adalah:

a. Pembentukan dan pembekalan Kelompok Siswa

Tim pelaksana diundang untuk mengadakan pertemuan persiapan pelaksanaan dengan melibatkan LPPkM Universitas PGRI Palembang. Tim pelaksana kemudian diberikan pembekalan mengenai maksud, tujuan, rancangan mekanisme program PKM, dan beberapa hal teknis berkaitan dengan metode/teknik pelaksanaan.

b. Penyusunan program sosialisasi

Berdasarkan hasil identifikasi, hasil analisis permasalahan yang ada, hasil analisis kebutuhan, dan hasil analisis potensi, selanjutnya disusun program sosialisasi.

2. Tindakan

Tindakan dalam kegiatan ini berupa implementasi Program. Kegiatan-kegiatan yang dilakukan dalam implementasi program adalah (a) pembentukan kelompokkelompok internet siswa (b) meningkatkan pengetahuan dan pemahaman anak bagaimana menggunakan (praktik) internet (c) sosialisasi bahaya, peraturan dan bentuk-bentuk perlindungan penggunaa internet.

3. Observasi dan Evaluasi

Observasi dilakukan terhadap bagaimana penggunaan internet yang dilakukan oleh siswa. Instrumen yang digunakan berupa catatan lapangan. Beberapa hal yang diobservasi adalah kendala-kendala, kekurangan-kekurangan, dan kelemahankelemahan yang muncul dalam proses di lapangan maupun dalam proses penggunaan internet oleh siswa. Evaluasi dilakukan terhadap kuantitas dan kualitas penggunaan serta pengetahuan terkait perlindungan pengguna internet.

4. Refleksi

Refleksi dilakukan terhadap kegiatan yang telah dilaksanakan. Hal ini dilakukan semata-mata untuk mengetahui kekurangan-kekurangan atau kelebihankelebihan terhadap kegiatan-kegiatan yang telah dilakukan dalam rangka untuk menetapkan rekomendasi terhadap keberlangsungan atau pengembangan kegiatankegiatan berikutnya. 


\section{HASIL DAN PEMBAHASAN}

SMA Negeri 1 Sungai Liat merupakan salah satu sekolah menengah atas di Provinsi Kepulauan Bangka Belitung. Layaknya sekolah menengah lainnya, SMA Negeri 1 Sungai Liat juga menerapkan kurikulum dan waktu menempuh pendidikan yang sama dengan sekolah menengah lainnya yakni 3 (tiga) tahun dari kelas X hingga kelas XII. Pemilihan SMA Negeri 1 Sungai Liat sendiri sebagai tempat pelaksanaan bukan tanpa alasan. Universitas PGRI Palembang memiliki niat agar daerah di luar dari Sumatera Selatan secara umum dapat merasakan manfaat dari keberadaan Universitas PGRI Palembang. Hal inilah yang melatarbelakangi mengapa SMA Negeri 1 Sungai Liat menjadi pilihan tempat PKM. Selain itu, siswa yang dipilih adalah kelas XII, dengan harapan proses sosialisasi terkait bahaya dan perlindungan penggunaan internet dapat diturunkan kepada siswa lain di kelas X dan XI.

Adapun kegiatan awal yang dilakukan tim Pengabdian Kepada Masyarakat (PKM) di SMA Negeri 1 Sungai Liat adalah kegiatan perencanaan. Kegiatan perencanaan didahului dengan mengundang tim pelaksana untuk mengadakan pertemuan persiapan pelaksanaan dengan melibatkan Lembaga Penelitian dan Pengabdian Kepada Masyarakat (LPPKM) Universitas PGRI Palembang. Dalam pertemuan tersebut kemudian didapatkan hasil berupa hasil identifikasi, hasil analisis permasalahan, analisis kebutuhan, hasil potensi sekolah. Hasil-hasil ini kemudian disusun untuk dibuat semacam program pelatihan yang sesuai dengan kebutuhan sekolah khususnya siswa.

Tindakan dalam kegiatan ini berupa implementasi dari program pelatihan yang telah dirancang sebelumnya. Adapun kegiatan-kegiatan yang dilakukan dalam program PKM di SMA Negeri 1 Sungai Liat antara lain, Pertama, pembentukan kelompokkelompok diskusi siswa. Pada awalnya tim PKM berencana untuk membagi siswa kelas XII menjadi 2 (dua) kelompok agar materi lebih focus. Namun terkait hal-hal teknis seperti ruangan dan waktu pelaksanaan, maka kegiatan dilakukan dengan menggunakan hanya satu ruangan serta peserta yang berjumlah 60 orang digabung menjadi satu. Kedua, identifikasi pengetahuan dan pemahaman awal siswa mengenai praktik dan perlindungan pengguna internet. Pada proses identifikasi awal ini, tim PKM memberikan semacam tes awal (pre-test). Tes yang diberikan berjumlah 4 (empat) soal berbentuk uraian. Hal-hal yang ditanyakan antara lain adalah, (a) Apakah siswa merupakan pengguna internet/media sosial?, (b) Apakah siswa mengetahui bahayabahaya dari penggunaan internet/media sosial? Sebutkan minimal 2 buah! (c) Apakah siswa dapat menjelaskan mengenai hoax, body shaming, dan cyber crime?, (d) Apakah siswa tahu terkait perlindungan (peraturan) yang melindungi pengguna dalam berinternet/ber-media sosial?.

Setelah dilakukan pre-test, maka didapat hasil bahwa (a) hampir semua siswa (60 orang) menggunakan internet/media sosial. (b) Hampir 40 orang siswa mengaku tahu bahaya internet walaupun tidak semua mampu memberi contoh dengan benar. (c) Dari 60 orang siswa, hanya 11 orang $(18,3 \%)$ yang mampu menjelaskan mengenai hoax, body shaming, dan cyber crime. (d) Pada soal terak hir, dari 60 orang siswa hanya 3 orang $(3,3 \%)$ yang mengetahui (walaupun tidak benar) terkait peraturan/perlindungan terhadap pengguna internet dan media sosial. Untuk lebih jelasnya dapat dilihat pada tabel 1 berikut : 


\section{Keterangan :}

\begin{tabular}{|c|c|c|c|c|}
\hline No & $\begin{array}{l}\text { No } \\
\text { Soal }\end{array}$ & $\begin{array}{l}\text { Jawaban } \\
\text { Benar }\end{array}$ & Jumlah* & Keterangan \\
\hline \multirow[t]{2}{*}{1} & (a) & $\sum$ & 60 & \multirow{2}{*}{$\begin{array}{l}\text { Terjawab } \\
\text { semua }\end{array}$} \\
\hline & & $\%$ & 100 & \\
\hline \multirow[t]{2}{*}{2} & (b) & $\sum$ & 40 & \multirow{2}{*}{$\begin{array}{l}\text { Terjawab } \\
\text { semua, } \\
\text { contoh } \\
\text { tidak tepat }\end{array}$} \\
\hline & & $\%$ & 66,7 & \\
\hline \multirow[t]{2}{*}{3} & (c) & $\sum$ & 11 & \multirow{2}{*}{$\begin{array}{l}\text { Terjawab } \\
\text { semua, } \\
\text { penjelasan } \\
\text { masih } \\
\text { kurang }\end{array}$} \\
\hline & & $\%$ & 18,3 & \\
\hline \multirow[t]{2}{*}{4} & (d) & $\sum$ & 3 & \multirow{2}{*}{$\begin{array}{l}\text { Terjawab, } \\
\text { tahu, } \\
\text { namun } \\
\text { kurang } \\
\text { tepat }\end{array}$} \\
\hline & & $\%$ & 33,3 & \\
\hline
\end{tabular}

(*) Jumlah siswa yang diberikan sosialisasi dan pre-test berjumlah 60 orang secara keseluruhan.

Setelah mendapatkan hasil dari pre-test, maka tim PKM yang berjumlah 7 (tujuh) orang kemudian melakukan proses sosialisasi masing-masing selama kurang lebih 15 menit. Pada kesempatan pertama, sosialisasi dilakukan oleh Ibu Ermini, S.H., M.M dengan materi mengenai "Generasi Milenial Sebagai Agent of Change di Era Revolusi Industri 4.0". Kemudian dilanjutkan oleh Ibu Sri Wahyuningsih, S.H., M.H dengan materi "Cyber Crime Sebagai Bentuk Kejahatan Dalam Penggunaan Internet Dikalangan Generasi Milenial". Pada sesi ketiga sosialisasi dilakukan oleh Ibu Dra. Hj. Jumroh, M.Pd dengan materi mengenai "Gerakan Internet Sehat", dilanjutkan dengan materi mengenai "Wanprestasi Jual Beli Online" yang disampaikan oleh Ibu Sri Husnulwati, S.H., M.H. Sosialisasi mengenai perlindungan dilakukan oleh Bapak Layang Sardana, S.H., M.H dengan materi "Etika Bermedia Sosial", dilanjutkan dengan materi oleh Bapak Ramanata Disurya, M.H mengenai "Peran UU ITE Dalam Etika Berkomunikasi di Dunia Maya. Sosialisasi kemudian ditutup dengan materi mengenai "Akibat Hukum Penyebaran Berita Bohong (Hoax) di Media Sosial" oleh Ibu Suryati, M.H. Setelah proses sosialisasi oleh pemateri, maka dilakukan proses Tanya jawab. Peserta sangat antusias, hal ini terlihat dari banyaknya siswa yang bertanya mengenai materi yang telah disampaikan. 


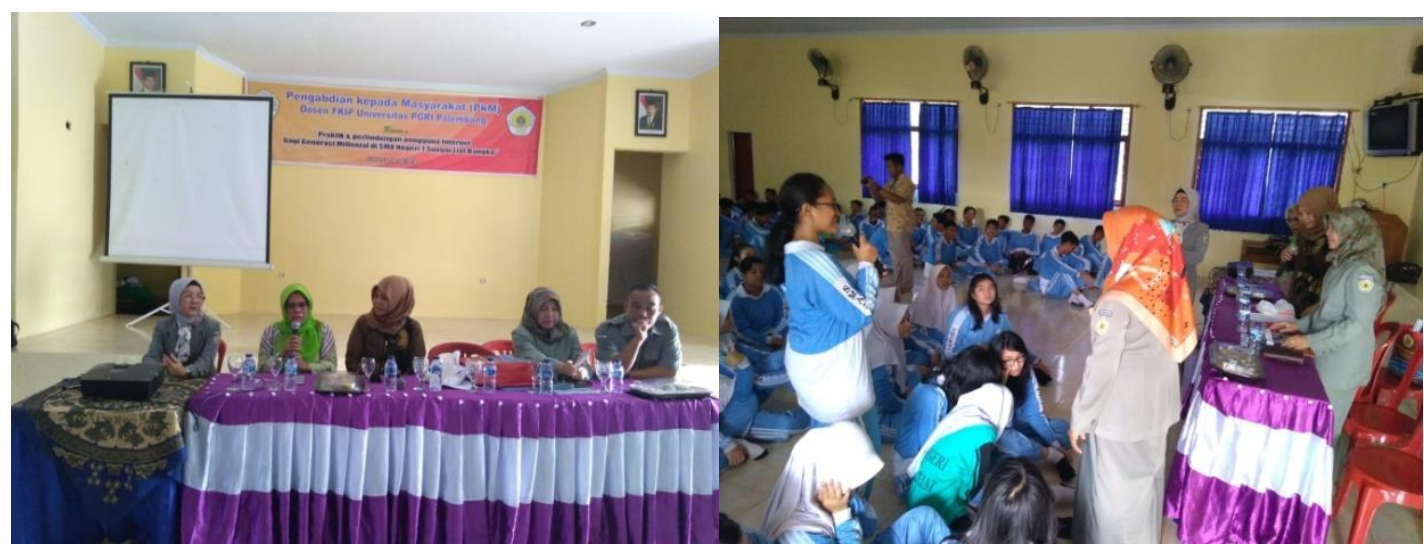

Gambar 1. Dokumentasi Kegiatan Sosialisasi di SMA N 1 Sungai Liat

Proses sosialisasi dan tanya jawab selesai, kemudian tim PKM melakukan semacam Post Test (dengan 4 pertanyaan uraian). Pertanyaan yang dipakai adalah pertanyaan pada saat Pre Test (soal b, c, dan d) serta ditambah satu soal mengenai langkah-langkah menggunakan internet secara sehat. Hal ini dilakukan untuk mengetahui bagaimana pemahaman dan efektifitas penjelasan materi oleh narasumber. Adapun hasil dari post test adalah sebanyak 55 orang siswa $(91,6 \%)$ mengetahui dan dapat memberikan contoh dengan benar mengenai bahaya internet. Sebanyak 51 orang siswa (85\%) mampu menjelaskan mengenai hoax, body shaming dan cyber crime dengan baik. Pada pertanyaan ketiga, terdapat sekitar 45 orang $(75 \%)$ yang mampu menyebutkan dan menjelaskan bentuk peraturan perlindungan terhadap pengguna internet/media sosial. Sedangkan pada pertanyaan terakhir, seluruh siswa (60 orang) mampu menjelaskan cara-cara bagaimana menggunakan internet secara sehat. Untuk lebih jelasnya dapat dilihat pada tabel 2 berikut :

Tabel. 2. Hasil Post-Test Siswa PKM di SMA N 1 Sungai Liat

\begin{tabular}{|c|c|c|c|c|}
\hline No & No Soal & $\begin{array}{l}\text { Jawaban } \\
\text { Benar }\end{array}$ & Jumlah* & Keterangan \\
\hline 1 & Soal (a) & $\sum_{\%}$ & $\begin{array}{c}55 \\
91,6\end{array}$ & Terjawab semua \\
\hline 2 & Soal (b) & $\sum_{\%}$ & $\begin{array}{l}51 \\
85\end{array}$ & Terjawab semua, contoh tepat \\
\hline 3 & Soal (c) & $\sum_{\%}$ & $\begin{array}{l}45 \\
75\end{array}$ & Terjawab semua, penjelasan baik \\
\hline 4 & Soal (d) & $\sum_{\%}$ & $\begin{array}{c}60 \\
100\end{array}$ & Terjawab, tepat \\
\hline
\end{tabular}

Sumber : Hasil olahan penulis (2019)

Keterangan :

(*) Jumlah siswa yang diberikan sosialisasi dan post-test berjumlah 60 orang secara keseluruhan.

\section{Evaluasi Kegiatan Sosialisasi}

Selain terkait pemahaman siswa pada saat menerima materi sosialisasi, pengukuran juga tim lakukan terkait bagaimana kegiatan sosialisasi berlangsung. Pengukuran ini dimaksudkan untuk memberi tolak ukur terkait peningkatan kinerja tim PKM pada kegiatan selanjutnya. Serta peningkatan tim PKM lainnya secara umum. Proses evaluasi yang tim lakukan adalah dengan memberikan semacam kuisioner dengan jumlah pertanyaan sekitar 13 buah dengan rincian 11 pertanyaan berbentuk 
pilihan 1 hingga 5 ( 1 = sangat kurang baik, 5 = sangat baik $)$ dan 2 pertanyaan berbentuk uraian.

Setelah dilakukan analisis terkait jawaban pada setiap pertanyaan maka didapat hasil bahwa sekitar 37 (63\%) menyatakan bahwa kegiatan sosialisasi sangat relevan bagi mereka sedangkan sekitar 14 orang (23\%) menyatakan relevan dan sekitar 9 orang (15\%) menyatakan cukup relevan. Terkait dengan isi sosialisasi, sekitar 33 orang (55\%) menyatakan sangat baik, sedangkan sekitar 27 orang (45\%) menyatakan isi sosialisasi baik. Mengenai bahan sosialisasi sekitar 24 orang (40\%) menyatakan sangat baik, 30 orang $(50 \%)$ menyatakan baik sedangkan sekitar 6 orang $(10 \%)$ menyatakan cukup baik. Mengenai narasumber yang memberikan sosialisasi, sekitar 6 orang $(10 \%)$ menyatakan narasumber telah sangat baik menyampaikan, 30 orang $(50 \%)$ menyatakan baik dan 24 orang (40\%) menyatakan cukup baik. Sedangkan mengenai kegiatan secara umum, sekitar 18 orang (30\%) menyatakan kegiatan telah berjalan sangat baik, 36 orang $(60 \%)$ menyatakan berjalan baik dan sekitar 6 orang (10\%) menyatakan berjalan cukup baik.

Terkait kejelasan tujuan sosialisasi, sekitar 24 orang (40\%) menyatakan tujuan sangat jelas, 24 orang (40\%) menyatakan jelas dan 12 orang (20\%) menyatakan cukup jelas. Mengenai agenda sosialisasi, sebanyak 18 orang $(30 \%)$ menyatakan agenda sosialisasi sangat jelas, 30 orang (50\%) menyatakan jelas dan 12 orang (20\%) menyatakan cukup jelas. Terkait dengan profesionalitas narasumber, sebanyak 30 orang $(50 \%)$ menyatakan sangat professional, 6 orang (10\%) menyatakan professional dan 24 orang $(40 \%)$ menyatakan cukup professional. Terkait fasilitas sosialisasi, sebanyak 18 orang (30\%) menyatakan fasilitas sangat baik, 6 orang (10\%) menyatakan baik, 24 orang $(40 \%)$ menyatakan cukup baik, 6 orang $(10 \%)$ menyatakan kurang baik dan sebanyak 6 orang (10\%) menyatakan fasilitas buruk. Dalam hal ketepatan waktu mulai dan selesainya sosialisasi, sebanyak 18 orang (30\%) menyatakan sangat tepat waktu, 24 orang $(40 \%)$ tepat waktu dan 18 orang $(30 \%)$ menyatakan cukup tepat waktu. Untuk kepuasan siswa terkait sosialisasi, maka sekitar 18 orang $(30 \%)$ menyatakan sangat puas, 18 orang (30\%) menyatakan puas, sedangkan sekitar 24 orang $(40 \%)$ menyatakan cukup puas.

Merujuk pada hasil rekapitulasi Pre Test dan Post Test yang dilakukan, serta jika dianalisis secara sederhana (tanpa uji statistik), maka dapat dilihat peningkatan secara jumlah siswa yang mengetahui terkait dampak dari penggunaan, bahaya serta perlindungan dari internet tersebut. Terkait dengan pengetahuan akan bahaya dari internet/media sosial terjadi peningkatan sebesar 48 orang (80\%). Untuk pengetahuan mengenai bahaya seperti hoax, body shaming, dan cyber crime mengalami peningkatan sejumlah 40 orang $(66,7 \%)$, sedangkan terkait perlindungan terhadap pengguna internet/media social terjadi peningkatan sejumlah 43 orang $(71,7 \%)$. Jika dihitung ratarata, peningkatan yang terjadi adalah sekitar $73 \%$. Hal ini tentu perlu dilakukan perhitungan kembali dengan metode yang lebih terukur dan valid.

Tabel. 3. Hasil Evaluasi Pengetahuan Siswa di SMA N 1 Sungai Liat

\begin{tabular}{cccc}
\hline \multicolumn{2}{c}{ Hasil Jawaban } & Peningkatan & $\%$ \\
Pre Test & Post Test & & Peningkatan \\
\hline 7 & 55 & 48 & 80,0 \\
\hline 11 & 51 & 40 & 66,7 \\
\hline 2 & 45 & 43 & 71,7 \\
\hline \multicolumn{7}{c}{ Rata-rata } & 44 & 73 \\
\hline
\end{tabular}

Sumber : Hasil Olahan Penulis (2019) 


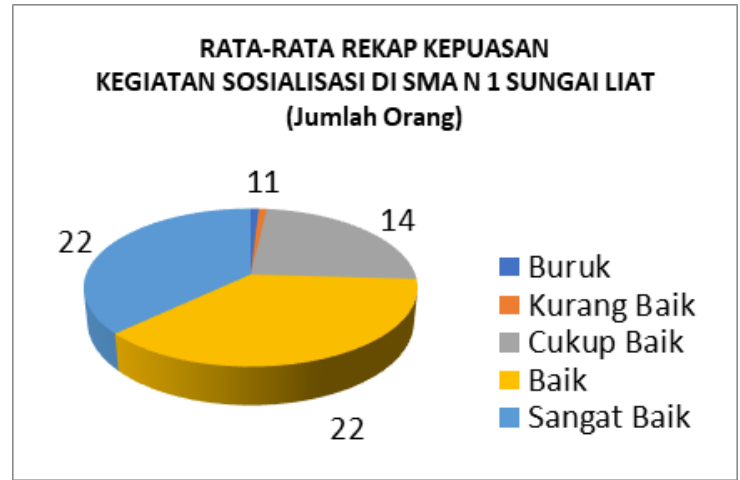

Gambar 2. Diagram Kepuasan Siswa pada Sosialisasi di SMA N 1 Sungai Liat

Terkait dengan pelaksanaan sosialisasi, secara keseluruhan maka mengenai kegiatan secara umum, sekitar 18 orang (30\%) menyatakan kegiatan telah berjalan sangat baik, 36 orang (60\%) menyatakan berjalan baik dan sekitar 6 orang (10\%) menyatakan berjalan cukup baik. Untuk kepuasan siswa terkait sosialisasi, maka sekitar 18 orang $(30 \%)$ menyatakan sangat puas, 18 orang $(30 \%)$ menyatakan puas, sedangkan sekitar 24 orang $(40 \%)$ menyatakan cukup puas. Jika melihat rata-rata (mean) secara keseluruhan sebenarnya cukup mengembirakan, hal ini dikarenakan siswa yang menyatakan kegiatan berjalan sangat baik dan baik adalah sekitar $37 \%$ (22 orang), cukup baik sekitar 24, 1 \% (14 orang) dan yang menyatakan kurang baik dan buruk sekitar $0,91 \%$ (1 orang). Walaupun begitu masih ada yang perlu dicermati terkait narasumber serta fasilitas yang secara jumlah dan presentase banyak yang belum puas sehingga perlu ditingkatkan.

\section{SIMPULAN}

Berdasarkan hasil pengabdian dan pembahasan yang telah diuraikan sebelumnya, maka dapat disimpulkan sebagai berikut : 1) Rata-rata siswa di SMA Negeri 1 Sungai Liat belum memiliki pemahaman terkait bahaya penggunaan internet serta perlindungan hokum pengguna internet/media social, hal ini terlihat dari hasil observasi awal serta hasil pre test. 2) Setelah dilakukan sosialisasi, siswa mulai memiliki pemahaman mengenai bahaya penggunaan internet, peraturan perlindungan pengguna serta bagaimana cara berinternet sehat. Hal ini ditunjukan dari hasil post test yang menunjukan pemahaman terkait materi sosialisasi. 3) Jika merujuk nilai kasar atas nilai pre test dan post test, terjadi peningkatan pemahaman rata-rata sebesar $\pm 73 \%$. Pelaksanaan, sosialisasi, partisipasi dan motivasi berjalan dengan cukup baik, hal ini dikarenakan siswa yang menyatakan kegiatan berjalan sangat baik dan baik adalah sekitar $37 \%$ (22 orang), cukup baik sekitar $24,1 \%$ (14 orang) dan yang menyatakan kurang baik dan buruk sekitar $0,91 \%$ (1 orang). Namun demikian, berdasarkan hasil pelaksanaan yang telah dilaksanakan maka disarankan perlu kiranya dilakukan program pengabdian dengan waktu yang lebih lama serta metode pengukuran yang lebih baik, agar dapat terukur secara kuantitatif dan baik secara kualitas pengabdian.

\section{DAFTAR PUSTAKA}

Greenlaw, R., \& Hep, E. (2001). Inline/online: fundamentals of the internet and the world wide web. Osborne: McGraw-Hill 
Hoffman, P. dan Harris, S.. (2006). The Tao of IETF: A Novice's Guide to the Internet Engineering Task Force. Network Working Group. Michigan. Jakson, Linda A., Barbatsis, Gretchen, Eve, Alexander von, Biocca, Frank, Zhao,

Jackson, L. A., Barbatsis, G., Von Eye, A., Biocca, F. A., Zhao, Y., \& Fitzgerald, H. E. (2003). Implications for the digital divide of Internet use in low-income families. IT \& Society, 1(5), 219-244.

Kementerian Komunikasi dan Informatika Indonesia. (2013). Internet Sehat dan Aman (INSANI).

Didapat

dari: https://kominfo.go.id/index.php/content/detail/3303/Internet+Sehat+dan+Aman + \%28INSAN\%29/0/internet_sehat\#.VRdpVWamByg.

Kemenkominfo. (2014). Siaran Pers Tentang Riset Kominfo dan UNICEF Mengenai Perilaku Anak dan Remaja Dalam Menggunakan Internet. Tersedia di: http://kominfo.go.id/index.php/content/detail/3834/Siaran+Pers+No.+17PIHKOMINFO22014+tentang+Riset+Kominfo+dan+UNICEF+Mengenai+Perilaku+Anak+dan +Remaja+Dalam+Menggunakan+Internet+/0/siaran_pers\#.UxkwqYaQb40 [Diakses 26 Januari 2019].

Turban, E., Rainer, R. K., \& Potter, R. E. (2005). Introduction to Information Technology. New Jersey: John Wiley \& Sons. 